\title{
Energia fotovoltaica: avaliação da legislação setorial e de incidência solar nos municípios paranaenses
}

\section{Photovoltaic energy: sectoral legislation and the solar incidence evaluation for the municipalities of Paraná}

\author{
Emerson Zonel Inácio da Silva ${ }^{1}$ \\ Angel dos Santos Fachinelli Ferrarini ${ }^{2}$ \\ Alexandre Florindo Alves ${ }^{3}$
}

\section{RESUMO}

O estudo tem por objetivo identificar as regiões de maior potencial de implantação de novas usinas e unidades consumidoras de energia fotovoltaica. Além desses, verificar a incidência solar real e potencial nos municípios e levantar informações de unidades consumidores nas categorias de autoconsumo remoto e geração na própria unidade consumidora. $O$ texto apresenta a evolução das resoluções normativas em relação à geração distribuída de energia fotovoltaica no país. O estudo se utiliza da análise estatística descritiva e exploratória dos dados para apresentar os dados de incidência solar, por estações de ano, e o potencial de geração e a localização das usinas de energia fotovoltaicas no Paraná. Os resultados mostram que a legislação permitiu o avanço na instalação e distribuição da energia solar entre os diversos agentes econômicos após 2016. No entanto, as regiões que podem ser melhor aproveitadas para a ampliação da utilização de energia fotovoltaica, em termos de incidência solar, são as mesorregiões do Norte Central, Norte Pioneiro e Noroeste do Estado. A pesquisa mostra que a utilização de energia fotovoltaica seria uma opção a ser considerada no Paraná em futuras políticas públicas, ambientais e de renda.

Palavras- Chave: Energia Fotovoltaica, Incidência Solar, Paraná, Legislação.

\begin{abstract}
This study aims to identify the regions with the most significant potential for implementing new plants and photovoltaic energy consumer units. In addition to these, verify the real and potential solar incidence, and identify remote self-consumption and generation information on the consumer unit. The evolution of normative resolutions of photovoltaic energy in the country is informed. The study uses descriptive and exploratory statistical analysis to present data on solar incidence, by seasons, to generation potential in Paraná. The results showed that the legislation allowed the advance in the installation and distribution of solar energy among the various economic agents after 2016. However, the regions that can be better used to increase the use of photovoltaic energy, in terms of solar incidence, are North Central, North Pioneer and Northwest of the State. The research shows that the use of photovoltaic energy would be an option to be considered in Paraná in future public, environmental and income policies.
\end{abstract}

Keywords: Photovoltaic Energy, Solar Incidence, Paraná, Legislation.

JEL: R10, R11, K32.

\footnotetext{
${ }^{1}$ Graduando em Economia na Universidade Estadual de Maringá. E-mail: ra107796@uem.br

${ }^{2}$ Professora na Universidade Federal de Rondonópolis. E-mail: angel.ferrarini@ufr.edu.br

${ }^{3}$ Professor na Universidade Estadual de Maringá. E-mail: afalves@uem.br
} 


\section{INTRODUÇÃO}

A expansão de novas fontes de energia renovável tem avançado em todo o mundo na busca por tecnologias mais sustentáveis que impactem cada vez menos o meio ambiente. O Brasil, ao longo dos últimos anos, avançou no consumo e geração de energias alternativas à energia de usinas hidrelétricas, alterou e criou novas legislações e novas fontes de investimentos visando reduções futuras no impacto ambiental. Atualmente, o Brasil se destaca na produção limpa de energia por ser um dos países que tem maior participação de energia renovável do mundo, ficando em terceiro lugar no ranking de capacidade renovável instalada, atrás somente da China e dos Estados Unidos (ROSA, 2018).

De acordo com a Empresa de Pesquisa Energética (EPE), a energia gerada de fonte hídrica representa mais de $60 \%$ da matriz elétrica brasileira, sendo insuficiente para atender a demanda projetada para os próximos anos (2013-2050), que poderá elevar em até duas vezes em relação ao consumo atual (EPE, 2018). Dentre as opções de utilização de recursos renováveis, a energia solar fotovoltaica apresenta elevado potencial, uma vez que, a intensidade dos raios solares depende da latitude e da posição no tempo, o que torna o Brasil um país bem localizado geograficamente.

Segundo o relatório da Agência Nacional de Energia Elétrica (ANEEL, 2008), quase todas as fontes de energia - hidráulica, biomassa, eólica, combustíveis fósseis e maremotriz - são formas indiretas de energia solar. A matriz elétrica brasileira é internacionalmente considerada uma das mais limpas do mundo devido à grande participação de recursos elétricos renováveis. Entretanto, o desenvolvimento sustentável tem gerado discussões na sociedade brasileira quanto à necessidade de preservar os recursos naturais e de como continuar a promover o desenvolvimento socioeconômico das regiões. Para isto, a geração de energia elétrica com maior utilização de fontes renováveis e menor agressão ao meio ambiente (MAJI, 2019) tem avançado nas discussões no congresso nacional brasileiro, especialmente após 2012.

O Paraná é uma das principais regiões geradoras de energia elétrica proveniente de hidrelétricas. Entretanto, após a publicação da Resolução Normativa no 482 de 17 de Abril de 2012 (ANEEL, 2012), que estabeleceu as condições gerais para - acesso a microgeração e minigeração distribuída e a utilização dos sistemas fotovoltaicos conectados à rede elétrica (SFVCR) ampliou-se a utilização do sistema. Contudo, sua difusão no país ainda é lenta e necessidade de ampliação ao acesso a fontes de financiamentos e o acesso por meio de políticas públicas ainda é incipiente.

O avanço da tecnologia, a redução de preços, políticas públicas de geração de energia compartilhada e a possibilidade de integrar os espaços urbanos são razões que mostram a importância da energia solar como opção de energia limpa (FREITAS et al., 2018). Entretanto, estudos com a temática de geração e distribuição de energia solar fotovoltaica, bem como, a análise de incidência solar e potencialidades municipais ainda são incipientes em estudos regionais no Brasil.

Diante disso, o objetivo do estudo é identificar as regiões de maior potencial de implantação de novas usinas e empresas do setor. Além desses, verificar qual a incidência solar real e potencial nos municípios e ainda levantar informações quanto às unidades consumidores nas categorias de autoconsumo remoto e geração na própria unidade consumidora. Como contribuição, o estudo faz um levantamento bibliográfico do panorama da legislação sobre energia fotovoltaica e geração 
distribuída. Além desse, apresenta-se os valores médios de incidência solar, por estações do ano e destaca as unidades consumidoras nas modalidades autoconsumo remoto e geração na própria unidade consumidora.

O artigo é estruturado em cinco seções sendo esta a primeira. A segunda seção apresenta os principais conceitos e processos sobre a geração de energia de fonte solar e a legislação sobre geração distribuída. A terceira seção informa a fonte de dados e o método estatístico para explorar os dados. Na quarta seção os resultados são apresentados para volumes de incidência solar e potencial regional, bem como, a quantidade de unidades consumidoras no Paraná nas modalidades de geração distribuída. Por último, as considerações finais.

\section{A GERAÇÃO DE ENERGIA DE FONTE SOLAR - GERAÇÃO DISTRIBUÍDA}

A energia solar fotovoltaica (foto = luz e volt = eletricidade) é gerada por meio da conversão direta da luz do sol em eletricidade, através da potência solar instantânea que incide em um ponto específico (ANEEL, 2008). Em relação à energia fotovoltaica, o mercado de geração distribuída teve início em 2012 com a aprovação da Resolução Normativa no 482 de 2012, que criou e regulamentou o Sistema de Compensação de Energia Elétrica por meio da geração distribuída.

No entanto, o crescimento da utilização e transmissão desse tipo de energia ocorreu principalmente em 2017. Dantas e Pompermayer (2018) relacionam tal crescimento às atualizações normativas que incentivaram a energia distribuída e que se seguiram após a Resolução no 687 de 24 de novembro de 2015, que autorizou empreendimentos na geração compartilhada.

A utilização da radiação solar como fonte direta de energia pode ser obtida por efeito térmico ou fotovoltaico. O efeito fotovoltaico é utilizado estritamente para geração de energia elétrica e pode ser de dois tipos: Sistemas isolados (Off-Grid) e Sistemas conectados à rede (Grid-Tie). Os dois sistemas têm o mesmo objetivo básico de gerar energia (NEOSOLAR, 2019).

O sistema isolado consiste em quatro etapas: na primeira a radiação é absorvida por painéis de silício, chamados painéis fotovoltaicos responsáveis por transformar a radiação solar em energia; na segunda etapa o controlador de carga é responsável por evitar sobrecargas nas baterias, o que aumenta sua vida útil e seu desempenho; na terceira etapa as baterias são responsáveis por armazenar a energia elétrica para que o sistema continue sendo utilizado quando não houver sol - até então ela foi gerada como corrente contínua (DC) e para ser transformada em corrente alternada $(A C)$, ao passar por um inversor. ${ }^{4}$ Esse sistema autônomo é utilizado para regiões remotas ou onde o custo para se conectar à rede elétrica é elevado (NEOSOLAR, 2019)

O sistema conectado à rede (Grid-Tie) é utilizado quando se tem acesso à rede elétrica. Esse sistema dispensa o uso de baterias, pois o excedente produzido é lançado à rede pública. Nesse sistema, a energia gerada pelos painéis fotovoltaicos passa direto ao inversor Grid Tie que é responsável por transformar a corrente contínua em corrente alternada e sincronizar com a rede pública. Diferente do sistema anterior, a energia é direcionada ao relógio bidirecional que controla quanto de energia está sendo consumida ou injetada na rede pública. Ao conectar o sistema na rede

\footnotetext{
${ }^{4}$ A corrente do tipo alternada é conhecida por 110 ou 220 volts, sendo preferível à outra por questões de custo.
} 
pública abre-se a possibilidade de compartilhar a energia produzida. Tal efeito também é conhecido por geração distribuída (NEOSOLAR, 2019).

Diferente dos sistemas isolados onde a energia excedente é armazenada em baterias, os sistemas conectados à rede jogam o excedente na rede pública, tornando a energia fotovoltaica uma boa opção para o sistema de geração distribuída. Com isso, partes interessadas (empresas, empreendimentos comerciais, indústrias) podem se unir em cooperativas com o intuito de produzir a própria energia a partir do sistema de geração distribuída (ANTONIOLLI, 2018).

As iniciativas de energia compartilhada têm gerado novas formas de produção, financiamento e alterado relações de consumo nos diversos setores (MARTINS, 2016), com isso muitas empresas estão aderindo ao modelo de energia compartilhada que visa interligar partes interessadas em um sistema de condomínio, consórcio ou cooperativa na busca pela produção própria a partir de um sistema de micro ou minigeração distribuída.

Existem restrições que diferenciam as gerações distribuídas das usinas fotovoltaicas, o Sistema de Compensação de Energia Elétrica da ANEEL abrange somente a microgeração e minigeração distribuída. Na Resolução Normativa n 687 somente são consideradas microgeração distribuída as centrais geradoras de até $75 \mathrm{~kW}$ e que utilizem fontes renováveis, enquanto a minigeração distribuída diz respeito às centrais que têm potência instalada de $75 \mathrm{~kW}$ (quilowatt) à $5 \mathrm{MW}$, ou 3 MW para a fonte hídrica (ANEEL, 2015).

A geração de energia solar compartilhada viabiliza o acesso à energia solar para consumidores com limitações financeiras, de espaço, de localização (latitude, longitude que desfavorece a captação solar) para a instalação de painéis fotovoltaica em seus imóveis. Shakouri et al. (2017), destacam que esses usuários podem investir em grupos formando uma comunidade e compartilhar os benefícios do sistema fotovoltaico dentro dos modelos de geração compartilhada, o que reduz o custo de instalação e beneficia a todos os usuários.

Entretanto, a instalação e viabilização dos projetos de geração compartilhada dependem de fatores como: incentivos governamentais para a geração de energia renovável, programas de auxílios às famílias de baixa renda para reduzir o custo de implementação, localização, divulgação do mecanismo e processos sobre a geração compartilhada. Nesse sentido, a legislação tem avançado em relação à clareza quanto aos processos e a definição dos agentes geradores e das capacidades. No entanto, 0 processo de redução de incertezas sobre as garantias a subsídios na implantação, custos no processo de distribuição à rede ainda permanecem no cenário institucional brasileiro.

\section{Evolução da Legislação do Setor Fotovoltaico}

No Brasil, as resoluções promulgadas e seu ordenamento jurídico são essenciais para a formulação de políticas públicas em direção ao avanço do setor. $O$ Ministério de Minas e Energia (MME) é responsável por formular, implementar e supervisionar as políticas públicas, enquanto que a ANEEL é uma autarquia criada em 1997 vinculada ao MME e que regula a geração, transmissão, distribuição e comercialização de energia entre outras funções, a Empresa de Pesquisa Energética tem por finalidade prestar serviços de estudos e pesquisas ao setor energético (VIDAL, 2017), a estrutura hierárquica do setor visa garantir a formulação e adequação das atividades de energia no país. 
O marco para a energia solar ocorreu com a publicação de 17 de abril de 2012 com a Resolução no 482 de 2012 pela ANEEL (ANEEL, 2012). Essa resolução marcou a atividade por apresentar a primeira grande resolução com mais detalhes para 0 acesso a microgeração e minigeração distribuída e a utilização dos sistemas fotovoltaicos conectados à rede elétrica. Após essa resolução, a capacidade de geração elétrica instalada no Brasil avançou ao longo dos anos e atingiu 935 MegaWatts (MW) em 2017, os dados são apresentados Tabela 1.

\begin{tabular}{lllllllll}
\multicolumn{6}{l}{ Tabela 1 - Capacidade de geração elétrica instalada no Brasil, 2013-2017 (MW) } \\
\hline & 2013 & 2014 & 2015 & 2016 & 2017 & $\begin{array}{l}\text { \% } \\
(2017 / 2016)\end{array}$ & $\begin{array}{l}\text { Part. } \\
(2017)\end{array}$ \\
& & & & & & & \\
\hline Hidrelétrica & 86.018 & 89.193 & 91.650 & 96.925 & 100.275 & 3,5 & 63,8 \\
Termoelétrica & 36.528 & 37.827 & 39.564 & 41.275 & 41.628 & 0,9 & 26,5 \\
Nuclear & 1.990 & 1.990 & 1.990 & 1.990 & 1.990 & 0,0 & 1,3 \\
Eólica & 2.202 & 4.888 & 7.633 & 10.124 & 12.283 & 21,3 & 7,8 \\
Solar & 5 & 15 & 21 & 24 & 935 & 3.836 & 0,6 \\
\hline Total & $\mathbf{1 2 6 . 7 4 3}$ & $\mathbf{1 3 3 . 9 1 3}$ & $\mathbf{1 4 0 . 8 5 8}$ & $\mathbf{1 5 0 . 3 3 8}$ & $\mathbf{1 5 7 . 1 1 2}$ & $\mathbf{4 , 5}$ & $\mathbf{1 0 0}$
\end{tabular}

Fonte: Adaptação do Anuário Estatístico de Energia Elétrica (EPE, 2018).

Esse avançou deu-se, especialmente, após o período de ajuste da Resolução Normativa no687 de 24 de novembro de 2015, que promoveu a transparência na classificação da distribuição de energia solar entre os diversos modelos de geração distribuída possíveis. Após essa resolução, a expansão da capacidade de geração elétrica instalação no Brasil na modalidade solar saltou 3.836\% entre 2916 e 2017 . A tabela 1 mostra que apesar da introdução da Resolução Normativa no482 ter ocorrido em 2012, a expansão da capacidade de geração foi lenta até 2016 e o salto ocorreu somente em 2017, provavelmente devido aos ajustes feitos nas resoluções seguintes a 2012.

A Resolução no 482 de 2012 especificava o processo de compensação de energia (met metering), isto é, como as unidades consumidoras seriam compensadas por toda a energia gerada e enviada à rede da distribuidora. No entanto, a resolução apresentava limitações e entraves burocráticos que dificultavam o acesso e ampliação do sistema. Segundo Vidal (2017) após uma consulta pública, a ANEEL aprovou a nova resolução no 687 de 2015, com novos parâmetros para a definição de microgeração e procedimentos de distribuição. Uma das mudanças refere-se ao prazo para o uso da energia elétrica excedente emprestada à rede distribuidora, que passou de 36 para 60 meses após a data do faturamento, definição, em detalhes, do que é microgeração distribuída e minigeração, bem como a criação e/ou modificação dos incisos referentes a geração compartilhada, dando mais clareza ao texto e ao processo.

O Banco de Informações de Geração da ANEEL fornece informações sobre as usinas em operação para o ano de 2018 e, dessa forma, pode-se formar um comparativo entre a potência que foi instalada naquele ano e o acumulado na rede em cada ano para o Brasil (Tabela 2). Os dados apresentam a evolução comparativa do crescimento potencial acumulado e o potencial instalado de 2014 até 2019 (1ํㅜ trimestre). 
Tabela 2 - Comparativo entre potencial instalado e acumulado, Brasil, 2014-2019 (Mega Watts -MW)

\begin{tabular}{llllllllllll} 
& 2014 & 2015 & $\Delta \%$ & 2016 & $\Delta \%$ & 2017 & $\Delta \%$ & 2018 & $\Delta \%$ & 2019 & $\Delta \%$ \\
\hline Instalada & 9 & 11 & 22 & 31 & 244 & 938 & 10.322 & 826 & 9.078 & 284 & 3.056 \\
& & & & & & & & & & & \\
Acumulada & 14 & 25 & 79 & 56 & 300 & 995 & 7.007 & 1820 & 12.900 & 2105 & 14.936 \\
\hline
\end{tabular}

Fonte: Elaboração com base nos dados da ANEEL (2018).

O avanço dos MW ao longo dos últimos anos é perceptivo e em grande parte incentivado por políticas de incentivos tributários (ICMS principalmente), bem como, pelo processo de evolução das resoluções e seus aditivos quanto à transparência das informações e clareza na elaboração das novas normativas.

O grande potencial de expansão das energias renováveis, e em específico da energia fotovoltaica, ocorre devido a alguns programas e políticas governamentais de apoio à indústria fotovoltaica, que a partir de 2015 ampliaram os tipos de empreendimentos aceitos. A Figura 1 mostra a linha do tempo dos principais instrumentos de apoio ao setor fotovoltaico no Brasil a partir de 1997.

Em 12 de dezembro de 1997 o Ministro da Fazenda junto aos Secretários de Fazenda, Finanças dos Estados e do Distrito Federal resolveram celebrar o Convênio 101/1997 (CONFAZ, 1997), que concedia a isenção do Imposto sobre Circulação de Mercadorias e Serviços (ICMS) nas operações com equipamentos e componentes para o aproveitamento das energias solar e eólica. A medida também incluía os geradores fotovoltaicos desde que houvesse alíquota de $0 \%$ ou isenção de Imposto sobre Produtos Industrializados (IPI) para esses produtos, nacionais e importados. Tal convênio entrou em vigor na data de sua publicação e teria duração até junho de 1998 , mas foi prorrogado 21 vezes sendo a última válida até 31 de dezembro de $2028^{5}$.

Figura 1 - Linha do tempo referente a legislação do setor de energia fotovoltaíca, Brasil, 1997-2017.

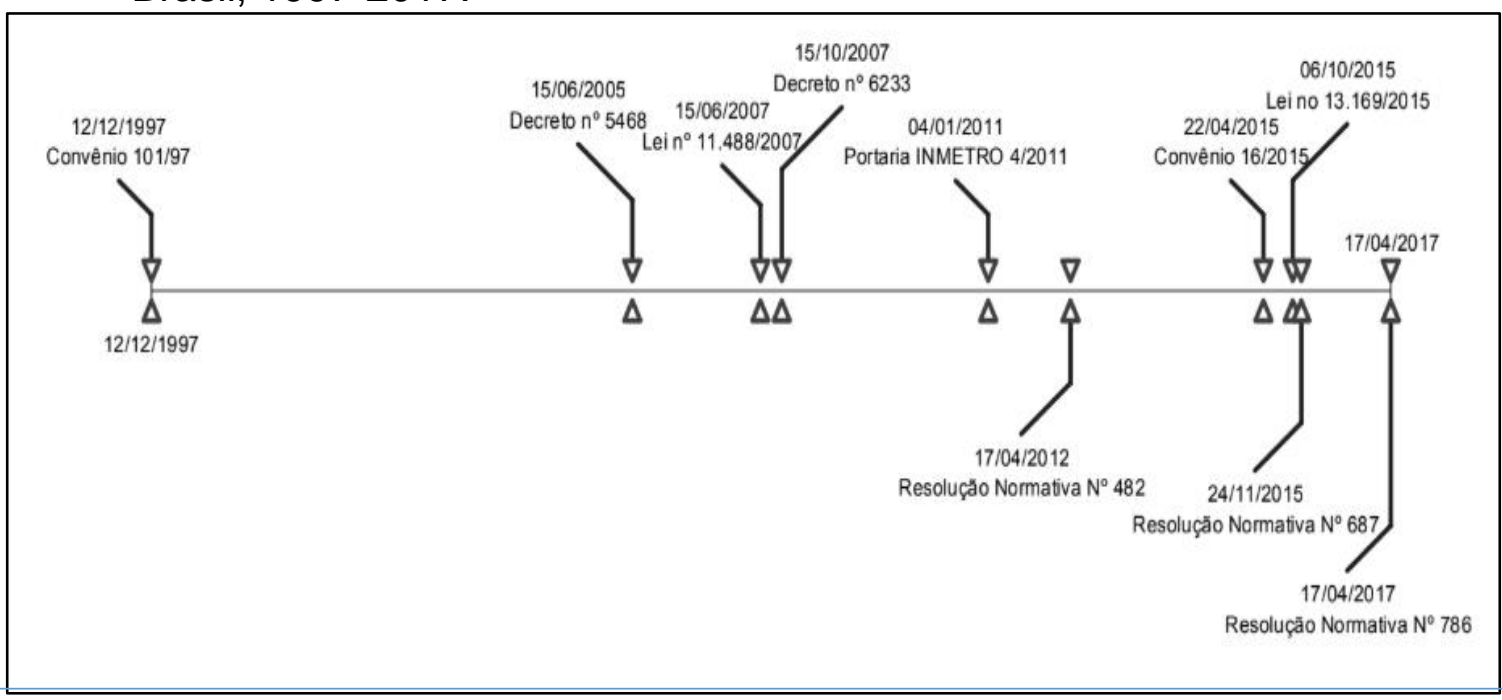

Fonte: Elaborado pelos autores.

Mais de 7 anos se passaram até o Decreto no 5.468 de 15 de junho de 2005 em que o Presidente da República isentou o IPI dos produtos utilizados para a geração

${ }^{5}$ O convênio ICMS 156 de 10 de novembro de 2017 prorroga o convênio 101 de1997 até 2028. 
de energia solar. Em 15 de junho de 2007 foi instituído o Regime de Incentivos para o Desenvolvimento da Infraestrutura (REIDI) por meio da Lei ํo 11.488. O REIDI implicava a suspensão da contribuição para o Programa de Integridade Social e de Formação do Patrimônio do Servidor Público (PIS/PASEP) e da Contribuição para o Financiamento da Seguridade Social (COFINS) sobre projetos voltados à implementação de infraestrutura nos setores de transporte, portos, energia, saneamento básico e irrigação, texto que foi posteriormente revogado até o atual decreto em vigor ㄲo 8.950 de 29 de dezembro de 2016, no qual aprova a tabela de incidência do imposto sobre produtos industrializados, revogando diversos decretos anteriores (BRASIL, 2016).

Ainda sobre a isenção de PIS/PASEP, COFINS e IPI, foi estabelecido em 11 de outubro de 2007 um Programa de Apoio ao Desenvolvimento Tecnológico da Indústria de Semicondutores (PADIS), reduzindo a zero as alíquotas de contribuição de PIS/PASEP, COFINS e IPI para pessoas jurídicas que realizem investimentos em pesquisa e desenvolvimento de dispositivos eletrônicos semicondutores incluindo células fotovoltaicas.

Em 4 de janeiro de 2011 o Presidente do Instituto Nacional de Meteorologia, Normalização e Qualidade Industrial (INMETRO) aprovou a revisão dos requisitos de avaliação da conformidade para sistemas e equipamentos para Energia Fotovoltaica considerando a necessidade de zelar pela eficiência dos equipamentos para energia fotovoltaica bem como a necessidade de estabelecer requisitos mínimos de desempenho e segurança.

Segundo Tiepolo et al. (2016) até maio de 2016, cerca de 16 estados haviam aderido à isenção do ICMS, o Estado do Paraná aderiu a isenção em 2018. Essas modalidades de políticas públicas que visam a redução de carga tributária para incentivar a utilização de energia renovável são importantes para garantir o acesso à tecnologia. Além disso, com o crescimento populacional e o aumento de renda mundial, o acesso e o consumo de energia proveniente de fontes renováveis poderia promover a melhoria da qualidade de vida e benefícios ao meio ambiente (GLENN et al., 2011).

\section{Legislação sobre a Geração Distribuída}

Na normativa $\mathrm{n}$ - 482 de 2012 a microgeração ocorria em situações menores ou iguais a $100 \mathrm{KW}$, enquanto na normativa no 687 de 2015 a microgeração passou a ser menor ou igual a $75 \mathrm{KW}$. Além dessa alteração importante, a minigeração que era considerada em geração superior a $100 \mathrm{KW}$ e menor ou igual a $1 \mathrm{MW}$ passou a ser considerada na normativa no 687 de 2015 como as gerações superiores a $75 \mathrm{KW}$ e menores ou igual a 5MW. Além dessa importante alteração, o prazo para o uso da energia elétrica excedente passou de 36 meses para 60 meses e o sistema de compensação Net Metering foi mantido.

Uma das modificações mais importantes entre essas duas resoluções foi a modalidade de entendimento do que é considerado como unidade consumidora. Anteriormente a Normativa no 482 de 2012 classificava somente microgeração distribuída e minigeração distribuída. A normativa no 687 de 2015 passou a classificar além dessas duas, os empreendimentos com múltiplas unidades consumidoras, geração compartilhada e autoconsumo remoto.

A Lei no 13.169 de 2015, entre outras disposições, no artigo 8o reduz a zero as alíquotas de contribuição de PIS/PASEP, COFINS e IPI incidentes sobre a energia elétrica ativa fornecida pela distribuidora à unidade consumidora, na quantidade 
correspondente à soma da energia elétrica ativa injetada na rede de distribuição pela mesma unidade consumidora, nos termos do Sistema de Compensação de Energia Elétrica para microgeração e minigeração distribuída (BRASIL, 2015) uma importante alteração e incentivo a geração.

O inciso VI do Art. 2º da Resolução no 687 de 2015 da ANEEL diz que o empreendimento com múltiplas unidades consumidoras é caracterizado pela utilização da energia elétrica de forma independente, no qual cada fração com uso individualizado constitua uma unidade consumidora de uso comum, ou seja, são os condomínios. Esse inciso garante que diversas unidades consumidoras distintas, desde que localizadas na mesma propriedade ou em propriedades contíguas, possam utilizar da energia de origem fotovoltaica localizadas em uma mesma propriedade ou em propriedades contíguas (ANEEL, 2015).

O inciso VII do mesmo artigo fala sobre a geração compartilhada, sendo caracterizada pela reunião de consumidores, dentro da mesma área de concessão ou permissão, por meio de consórcio ou cooperativa, composta por pessoa física ou jurídica, que possua unidade consumidora com microgeração ou minigeração distribuída em local diferente das unidades consumidoras nas quais a energia excedente será compensada (ANEEL, 2015).

Esse inciso implica que não necessariamente o sistema de captação de energia fotovoltaica estará no mesmo lugar que o consumidor se encontra, abrindo portas para que um condomínio possa gerar sua energia em um lugar afastado por falta de espaço nos grandes centros urbanos. Por fim, o inciso VIII traz o caso mais básico, 0 autoconsumo remoto sendo caracterizado por unidades consumidoras de titularidade de uma mesma pessoa jurídica, incluídas matriz e filial, ou pessoa física que possua unidade consumidora com microgeração ou minigeração distribuída em local diferente das unidades consumidoras, dentro da mesma área de concessão ou permissão, nas quais a energia excedente será compensada (ANEEL, 2015).

O autoconsumo remoto diferencia a geração compartilhada por tratar de uma mesma pessoa, jurídica ou física, que possua unidades consumidoras em locais diferentes das unidades consumidoras com microgeração ou minigeração distribuída, possibilitando que uma mesma pessoa consiga utilizar a energia em outras residências, não somente na que foi gerada.

Essa resolução também definiu como seria o processo e o funcionamento do sistema de compensação de energia elétrica. Entretanto, em 17 de outubro de 2017 veio a atualização mais recente dessa resolução, a Resolução no 786 de 2017, que alterou os limites de potencial das centrais minigeração distribuída, central geradora de energia elétrica, com potência instalada superior a $75 \mathrm{~kW}$ e menor ou igual a $5 \mathrm{MW}$ e que utilize cogeração qualificada para todos os tipos de fontes renováveis (ANEEL, 2017).

Além dessas resoluções é importante ressaltar que em dezembro de 2015 o MME lançou um Programa de Desenvolvimento de Geração Distribuída de Energia Elétrica (ProGD) com apoio do Banco Nacional de Desenvolvimento Econômico e Social (BNDES), que visava a ampliação das ações de estímulo à geração de energia de fontes renováveis pelos consumidores, com destaque para a energia fotovoltaica. A previsão era a de que $R \$ 100$ bilhões fossem investidos até 2030 , com 2,7 milhões de consumidores gerando energia em residências, comércio e indústrias com a adesão de escolas federais e universidades (MME, 2015), no entanto os valores carecem de ampliação e de utilização.

A forma como a legislação sobre energia fotovoltaica e geração distribuída é normatizada no país é importante, trata-se do parâmetro a ser utilizado na formulação 
das políticas regionais. Algumas das possibilidades de políticas públicas implementadas em outros países visam: incentivos financeiros com a utilização de programas de fomento, políticas públicas para instalação de painéis, políticas para o compartilhamento de energia, políticas dirigidas à demanda, isenções fiscais e outras (Paulista et al., 2017), o que demonstra que o Brasil está no caminho, no entanto, os dados quanto ao acesso e a capacidade instalada ainda são escassos. A seção a seguir apresenta a base de dados e a metodologia.

\section{METODOLOGIA}

\section{Fontes dos dados}

O Atlas da Energia Solar disponível em Tiepolo et al. (2017) foi utilizado como base de dados para a verificação dos municípios no Paraná com maior incidência solar. Os dados são compostos por estimativas fornecidas pelo modelo BRASIL-SR baseadas em imagens de satélite coletadas entre 1999 e 2015 (17 anos) e validadas por dados observados em solo.

Os dados do Atlas mostram informações para quatro tipos de classificação de incidência solar em termos médios mensais, anuais, por estações do ano nas classificações denominadas de irradiação solar global, inclinada, difusa e direta incidente no território brasileiro em $\mathrm{Wh} / \mathrm{m}^{2} \cdot \mathrm{dia}^{6}$ e total anual em $\mathrm{Wh} / \mathrm{m}^{2}$.ano. Considerou-se nessa pesquisa a classificação de energia inclinada na latitude local (maximiza a captação da energia solar), essa classificação de energia refere-se à soma das energias da irradiação solar do tipo direta normal, direta difusa e a refletida que incide no plano horizontal após refletir de alguma outra superfície.

Além desse, o estudo se utilizou dos dados fornecidos pelo ANEEL (2019). Sobre as unidades consumidoras, por município, em relação a geração própria ou autoconsumo remoto nas categorias de comércio, indústria, residência e área rural. Os dados foram agregados para a identificação quanto a atual potência instalada ${ }^{7}$ no Paraná.

A base de dados do atlas solar separou em cerca de 4.600 polígonos todos os níveis de incidência solar nos municípios ${ }^{8}$ paranaenses para determinados dados de latitude e longitude. Utilizou-se o software Visual Studio 2017 para desenvolver um novo banco de dados com as informações agregadas do Atlas Solar e compatibilizar os dados com o número de municípios no Estado. Portanto, os polígonos foram agregados para a média de incidência solar em cada município do Estado do Paraná, o que permitiu a verificar a intensidade solar média para cada estação do ano (Primavera, Verão, Outono e Inverno) e em cada município (399).

\section{Método}

A pesquisa é quantitativa e exploratória de dados, se utiliza do software Geoda para a análise estatística descritiva e exploratória para gerar os mapas de Percentil e Quartil. Os dados georreferenciados contribuem para a interpretação e visualização das

\footnotetext{
${ }^{6} \mathrm{WH}$ (watt-hora) unidade de energia por hora. $\mathrm{Wh} / \mathrm{m}^{2}$ implica em watt-hora por metro quadrado, é a potência recebida por unidade de área.

${ }^{7}$ Potência instalada total das unidades consumidoras em quilowatt (KW) até o período de coleta do estudo (30/09/2019), ou seja, consumo potencial.

${ }^{8}$ Alguns municípios apresentam mais polígonos do que outros devido ao seu posicionamento solar, latitude, longitude, declividade, entre outros.
} 
informações utilizadas. Dentre as possibilidades, as imagens de percentil e de quartil utilizadas ilustram a localização dos dados coletados a fim de inferir estatisticamente a exploração das informações.

Dados de quartil e percentil são medidas separatrizes que foram utilizadas com dados agrupados em intervalos de classes. A frequência do percentil está dividida em seis agrupamentos que vão de percentil menor que $1 \%$, entre $1 \%$ e $10 \%$, entre $10 \%$ e $50 \%$, entre $50 \%$ e $90 \%$, entre $90 \%$ e $99 \%$ e acima de $99 \%$. Os dados de quartil (quantile) estão agrupados em seis agrupamentos de igual montante. As separatrizes são valores da distribuição que dividem em partes quaisquer (MORETTIN E BUSSAB, 2012).

Além desse, considerou-se a taxa de desempenho (TD) possível para os painéis solares, que reflete a relação entre a produtividade ( $\mathrm{KWh} / \mathrm{Kwp})$ e a quantidade de horas de Sol normalmente para um ano de operação e que são captadas pelos painéis (CRESESB, 2014). Esse valor representa o desempenho do sistema ${ }^{9}$ e a utilização do TD varia entorno de 0.7 a $0.8 \%$ da incidência no plano de latitude local. Assim, a produtividade da incidência considerada se refere a 0,7 da incidência média calculada.

\section{RESULTADOS E DISCUSSÃO}

\section{Potencial Fotovoltaico No Paraná}

O Estado do Paraná apresenta potencial elevado, com valores de irradiação total anual média de 4.972,25 Wh/m² ano (TIEPOLO et al., 2016). Entretanto, os resultados apresentados na Figura 2 mostram, por estação do ano, que a incidência solar média nos municípios Paranaenses diverge ao longo das estações do ano.

As maiores incidências de radiação solar ocorrem nas mesorregiões no Norte Central, Norte Pioneiro e Noroeste do Estado, ou seja, na região Norte do Estado do Paraná em todas as estações do ano. O mapa em percentil apresenta diferenças nas incidências solares entre as estações do ano nos municípios. O mapa para a Primavera (segunda estação de maior incidência solar) mostrou que os 4 municípios com incidência > 99\% (média de 5377 - $5387 \mathrm{Wh} / \mathrm{m}^{2}$.ano) são os municípios de Nossa Senhora das Graças, Guaraci, Cafeara, Santo Inácio, localizadas na mesorregião do Norte Central Paranaense.

Na estação Verão, a de maior incidência solar, os resultados mostram que os 4 municípios com incidência $>99 \%\left(5648-5713 \mathrm{Wh} / \mathrm{m}^{2}\right.$.ano) seriam Foz do Iguaçu, Santa Terezinha de Itaipu, Itaipulândia localizadas na mesorregião do Oeste Paranaense e o município de Diamante do Norte localizado na mesorregião Noroeste do Estado.

No Outono, o destaque volta a ser da mesorregião do Norte Central e os quatro municípios com incidência >99\% (5283-5306 Wh/m².ano) são Cafeara, Lupionópolis, Porecatu e Centenário do Sul. No Inverno, os resultados mostram que os 4 municípios com incidência >99\% (4881-4887 Wh/m².ano) sãos os municípios de Itaguajé, Cafeara, Miraselva e Centenário do Sul, todos da mesorregião Norte Central do Estado.

Os municípios de Cafeara e Centenário do Sul aparecem com municípios acima da média de incidência nas estações mais frias do ano (outono e inverno), esses

\footnotetext{
${ }^{9}$ Perdas nas conexões, variação de temperatura e outros podem reduzir o potencial de captação dos painéis fotovoltaicos.
}

138 Economia \& Região, Londrina (Pr), v.9, n.1, p.129-146, jan./jun. 2021 
municípios são pequenos e de pouca representatividade econômica no Estado do Paraná, ambos localizados na região Norte Central Paranaense, que apresenta outros municípios cuja a representatividade econômica para o Paraná e relevante, Maringá, por exemplo. No entanto, a elevada incidência solar identificada nessa região sugere que a formulação de políticas, ambientais e de renda, deveriam considerar a expansão da energia fotovoltaica como fonte de energia propulsora de diversificação na região.

Figura 2 - Intensidade de irradiação solar em Wh/m².ano em Percentil para o Paraná, 2019.

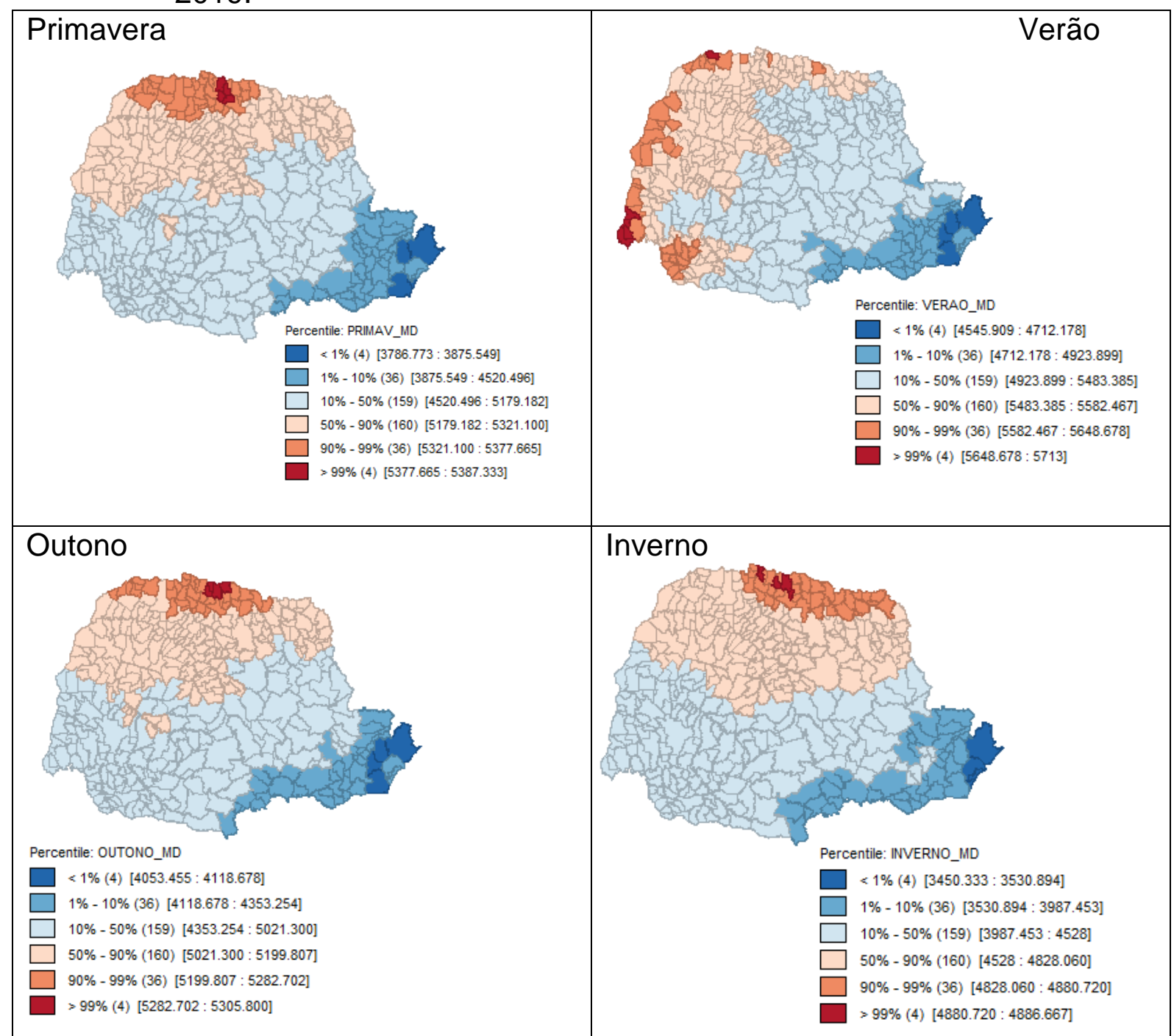

Fonte: Elaboração dos autores

As figuras apresentadas também destacam, as mesorregiões do Norte Central, Norte Pioneiro e Noroeste do Estado na classificação de 50\%-99\% de incidência, o que inclui, municípios de alto valor econômico e de desenvolvimento regional como Maringá (verão incidência: 5.451), Londrina (verão incidência: 5.358) e outros.

Esses resultados mostram a importância da incidência solar na formulação de políticas públicas de diversificação da matriz energética Paranaense, uma vez que, permite identificar regiões de maior e menor incidência, o que permitiria ao Estado formular políticas de desenvolvimento setorial e de diversificação do consumo de energia. Conforme destaca Olszewski et al. (2019), a possibilidade de um crescimento urbano desordenado tende a contribuir para as mudanças climáticas globais, e se faz 
necessário ampliar discussões entorno do planejamento urbano com o desenvolvimento sustentável dos municípios. Sendo o crescimento demográfico e a concentração em vias urbanas um processo ascendente na realidade mundial e, com base na incidência, os dados sugerem a possibilidade de ampliação das políticas sociais que visem a capacidade das cidades em atender as demandas de consumo de forma sustentável.

Outro mapa importante de ilustrar é o mapa de quartil (Figura 3). Nessa figura, duas estações do ano se destacam como as de maior incidência solar (Verão e Primavera), nesse caso é possível observar a uniformidade na incidência solar nas mesorregiões do Norte central, Norte Pioneiro, Noroeste do Estado, Oeste e Sudoeste Paranaenses.

Figura 3 - Intensidade de irradiação solar em Wh/m².ano em Quartil para o Paraná, 2019.

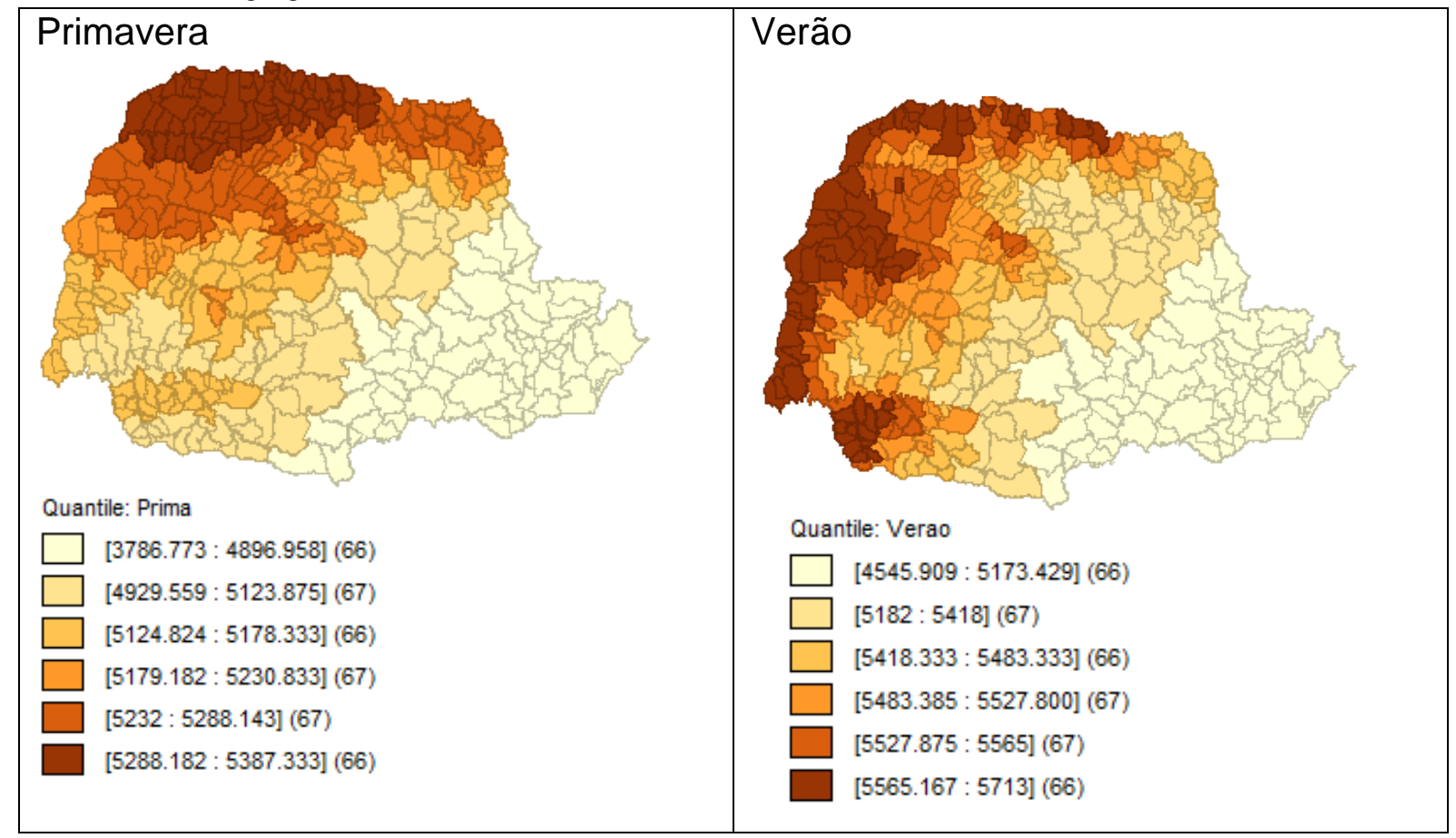

Fonte: Elaboração dos autores

A escala de cores representa os valores de irradiação solar média, de menor incidência ao de maior incidência, para as duas estações. A estação da Primavera concentra a maior incidência solar na Região Norte do Paraná enquanto que a estação Verão na Região Norte e Região Oeste do Estado. Os resultados mostram que a incidência solar nos municípios pode diferir nas estimativas da produção de energia elétrica ao longo do ano. Sendo assim, a formulação de políticas públicas que visem o avanço da geração compartilhada e o autoconsumo remoto podem beneficiar outras regiões de menor incidência solar na mesma época do ano.

Essas regiões representam elevada participação no PIB Paranaense. Segundo dados do IBGE (2019), a mesorregião do Norte Central representou 17.54\% do PIB, enquanto que, o Oeste Paranaense representou $12.64 \%$, ambas as regiões ficam atrás somente da região Metropolitana de Curitiba cuja a representatividade foi de 40.12 \% no ano de 2017, o que reforça a importância das regiões como propulsoras da diversificação na matriz energética do Paraná. 
O desempenho de um sistema fotovoltaico é tipicamente medido pela TD e tem suscitado pesquisas na área de desenvolvimento tecnológico e novos projetos (Çoban, 2018) para melhoria na eficiência dos sistemas. Assim, a Figura 4 mostra a irradiação total em $\mathrm{Kwh} / \mathrm{m}^{2}$.ano e a produtividade anual em $\mathrm{Kwh} / \mathrm{m}^{2}$ (TD) em 10 quartis, ou seja, permite identificar, em uma escala de igualdade, as regiões de maior e menor incidência com base na eficiência da utilização das placas. Nesse mapa, a produtividade anual refere-se a uma incidência anual (incluindo todas as estações do ano) que representa $70 \%$ da irradiação total $\mathrm{em} \mathrm{KWh} / \mathrm{m}^{2}$.

Figura 4 - Mapa Voltaico do Paraná, Irradiação e Produtividade Média Anual, 2019.

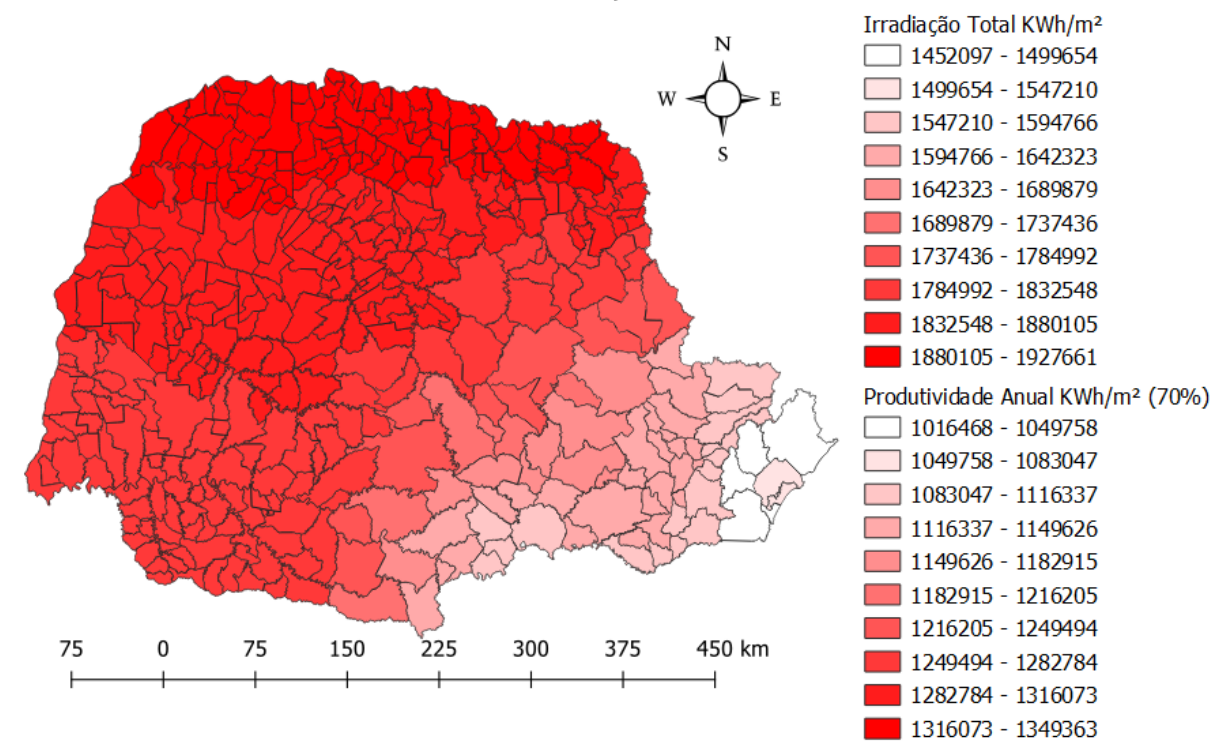

Fonte: elaboração dos autores no Qgis (2019).

Com a produtividade anual de energia solar pode-se observar quanto de energia um painel fotovoltaico consegue produzir ao longo do ano, em termos médios, e realizar comparações entre municípios. Estes dados mostram o grande potencial de geração fotovoltaica existente no Estado. Potencial que, a partir das novas regulamentações nacionais, pode ser ampliado com a discussão em âmbito estadual e a implantação de políticas de incentivo a sustentabilidade ambiental. A seção seguinte apresenta os dados das unidades consumidores nas modalidades de autoconsumo remoto e geração na própria unidade consumidora (UC), o potencial a ser ampliado ainda é bastante elevado.

\section{AUTOCONSUMO REMOTO E GERAÇÃO NA PRÓPRIA UC}

No Paraná existem quatro usinas de energia fotovoltaica que são registradas pela ANEEL; uma delas localizada no município de Curitiba (Usina Volpato) com potência fiscalizada de 0,46 kW e, em operação desde outubro de 2011, a segunda em São José dos Pinhais (cobertura do estacionamento da Renault) com potência de 19,60 kW em operação desde fevereiro de 2014, a terceira foi instalada em Sertanópolis (Usina Maxim Engenharia Elétrica) com potência fiscalizada de $2 \mathrm{~kW}$ em operação desde setembro de 2016 e a última em Rolândia (Usina Dallon Solar) com potência de $150 \mathrm{~kW}$ em operação desde outubro de 2018.

As usinas fotovoltaicas estão localizadas tanto em regiões de maior potencial solar (Região Norte) quanto nos de menor potencial (Região Metropolitana de 
Curitiba), o que corrobora para a discussão de uma política pública de incentivo a instalação de novas usinas em todo o Estado e que o volume de incidência solar não é o único determinante para a instalação de uma usina de energia fotovoltaica. Os municípios São José dos Pinhais e Curitiba não representam, necessariamente, municípios de maior potencial de irradiação solar (Figuras 2 e Figura 3). Entretanto, a região metropolitana de Curitiba apresenta uma das melhores regiões em condições socioeconômicas do Paraná, o que sinaliza que as questões de Regulação Normativas e isenções fiscais não são totalmente suficientes para a instalação de uma usina, questões sociais e econômicas, bem como, a capacidade de desenvolvimento regional são importantes determinantes para a instalação destas.

O município de Curitiba e São José dos Pinhais foram responsáveis pelas maiores participações no PIB regional. O município de Curitiba representou $20.1 \%$ da participação do PIB, seguido pelo município de São José dos Pinhais com participação de 5.36\% no ano de 2017 (IBGE, 2019). Entretanto, os municípios de Sertanópolis e Rolândia apresentaram participação no PIB de 0,17\% e 0,62\% no ano de 2017, inferiores aos de Curitiba e São José dos Pinhais, o que sugere que novas pesquisas que abordem a temática no contexto econômico e industrial são relevantes para a ampliação da discussão, além da renda e participação municipal na representatividade do PIB regional.

Além disso, se observa que as usinas de Sertanópolis e de Rolândia se encontram em uma região de elevada incidência solar em todo período do ano e apresentam valores acima da média do estado inteiro. A região Norte do Estado do Paraná apresenta boa diversidade socioeconômica, com empresas nos mais diversos setores e logística para a implementação de atividades e a proximidade com o Estado de São Paulo e Mato Grosso do Sul favorece a comercialização, o que poderia ter impulsionado a instalação das usinas nessas regiões.

A Figura 5 mostra o potencial gerado por município no Paraná, nas categorias de autoconsumo remoto e geração na própria unidade consumidora (UC).

Figura 5 - Autoconsumo remoto e a geração na própria UC para os municípios paranaenses até 30/09/2019.

\begin{tabular}{|l|l|}
\hline & \\
\hline &
\end{tabular}

Fonte: elaboração dos autores 
Os municípios com maiores unidades consumidoras na categoria de autoconsumo remoto foram Guarapuava $(274,73 \mathrm{~kW})$ e Coronel Vivida $(63,05 \mathrm{~kW})$, sendo que a primeira UC cadastrada no município de Guarapuava está datada de 27 de março de 2015 e a última de 25 de setembro de 2019. O município de Guarapuava é município de maior potência instalada e de melhor diversificação entre as atividades na utilização de energia solar, são 38 comércios, 3 indústrias, 57 residências, 2 propriedades na área rural além de 1 unidade consumidora no serviço público.

Em relação a geração na própria UC é a modalidade mais comum de todas, no qual o sistema de geração de energia fotovoltaico é instalado no mesmo ponto de conexão com a rede da distribuidora. Este sistema gera energia que será usada para abater o consumo da UC em questão, o que reduz a conta de luz dessa UC. Não é possível transferir créditos para outras UCs e o consumidor faz uso exclusivo do sistema de geração. Sendo assim, atualmente existem 5.216 UC no Paraná que se utilizam dessa modalidade.

Os dados em percentil destacam que 199 municípios apresentam algum agente econômico (comércio, indústria, área rural, residência) que na somatória geram até $38,440 \mathrm{~kW}$ de potência no município, 160 municípios com potência instalada entre 38,440 e 270,192 kw, 36 municípios com potência instalada de até $3.046 \mathrm{~kW}$ e 4 municípios com as maiores somas instaladas de $4.738 \mathrm{~kW}$. No caso das maiores potencias instaladas foram classificadas como comércio ou área rural. As unidades consumidoras com mais de $100 \mathrm{~kW}$ de potência instalada totalizaram $11 \mathrm{UC}$, sendo que 4 UC estão localizadas no município de Maringá.

De um modo geral, os resultados mostram que a viabilização da implantação de uma usina fotovoltaica e/ou unidades consumidoras nos municípios paranaenses vão além do nível de incidência solar e do potencial real de geração de energia (Figuras 5A e 5B). Além disso, o levantamento dos dados de legislação e as alterações nas regras quanto a geração, distribuição e créditos no mercado de energia Fotovoltaico ainda são incipientes, o que evidencia que as barreiras institucionais e políticas são questões de destaque frente ao aumento da demanda futura por energia elétrica. O desenvolvimento social, econômico é um importante diferencial para o avanço da diversificação da matriz elétrica paranaense

\section{CONSIDERAÇÕES FINAIS}

O presente estudo teve por objetivo identificar as regiões de maior potencial de implantação de novas usinas e empresas do setor. Além desses, verificar qual a incidência solar real e potencial nos municípios e ainda levantar informações quanto de unidades consumidores nas categorias de autoconsumo remoto e geração na própria unidade consumidora. Os resultados mostram que as modalidades de autoconsumo remoto e geração na própria unidade consumidora tem avançado no Paraná, especialmente em anos recentes, em parte, devido à evolução da legislação e a redefinição de isenções fiscais e volume gerado em todas as modalidades.

Os projetos voltados a implementação do sistema recebem incentivos fiscais (isenção de ICMS, PIS e Cofins na geração distribuída, redução do imposto de importação) de acordo com a natureza do projeto. Além disso, alguns outros benefícios são incentivados por parte do governo (Apoio BNDES, Plano Inova Energia e outros) que visam a redução de custos no processo de implantação de usinas e/ou condomínios com a geração compartilhada.

No entanto, o levantamento bibliográfico sobre a evolução da legislação setorial mostrou que ainda é preciso avançar em questões que promovam o desenvolvimento 
regional e na formulação de políticas públicas de incentivo a geração compartilhada e a instalação de painéis, bem como, a ampliação da educação e difusão do conhecimento quanto a importância da diversificação da matriz elétrica.

Os dados para a avaliação da incidência solar nos municípios paranaenses sugerem as regiões que possibilitariam uma melhor utilização da incidência solar ao longo do ano com feito comparativo entre os municípios. Entretanto, os dados mostram que a maior parte dos municípios paranaenses apresentam irradiação solar acima da média ao longo de todo o ano, ou seja, os dados destacam que a energia solar fotovoltaica é uma opção relevante para a formulação de políticas públicas que visem a sustentabilidade ambiental, bem como, para a expansão de atividades geradoras de renda e emprego nas regiões.

A incidência solar é um indicador importante para averiguar o potencial de geração de energia solar pelos painéis solares. Entretanto, questões sociais, econômicas, de distribuição de renda, nível de conhecimento e políticas públicas são variáveis que podem condicionar a instalação de uma usina, empresa, ou ampliar a utilização de energia fotovoltaica como geração distribuída em municípios com incidência solar abaixo da média no Estado.

Apesar de ser desejável, deve-se observar que discussões que envolvem estudos georreferenciados, legislação e políticas públicas para o Paraná ainda são carentes de discussões ampliadas. Sendo assim, as limitações desses estudos são obstáculos que podem amenizados com a ampliação de pesquisas regionais capazes de abordar políticas ambientais com ênfase nas diferenças econômicas, socioambientais capazes de inferir uma relação de causalidade.

\section{REFERÊNCIAS}

ANEEL. Atlas de Energia Elétrica do Brasil. Brasília: [s. n.], 2008. Disponível em:> http://www2.aneel.gov.br/arquivos/PDF/atlas3ed.pdf > Acesso em 13 fevereiro de 2019.

Resolução Normativa no 482, de 17 de Abril de 2012. Estabelece as condições gerais para o acesso de microgeração e minigeração distribuída aos sistemas de distribuição de energia elétrica, o sistema de compensação de energia elétrica, e dá outras providências. Publicado no D.O. de 19.04.2012, seção 1, p. 53, v. 149, n. 76.

Resolução Normativa № 687, de 02 de Dezembro de 2015. Altera a Resolução Normativa no 482, de 17 de abril de 2012, e os Módulos 1 e 3 dos Procedimentos de Distribuição - PRODIST. Publicado no D.O. de 02.12.2015, seção 1, p. 45 , v. 152 , n. 230.

Resolução Normativa no 786 , de 17 de outubro de 2017. Altera a Resolução Normativa no 482, de 17 de abril de 2012. Publicado no D.O. de 25/10/2017, Edição: 205, Seção: 1, Página: 56.

.Informações gerenciais. Relatório 2018. Brasília: [s. n.]. Disponível em:> https://www.aneel.gov.br/documents/656877/14854008/Boletim+de+Informa\%C3\%A 
7\%C3\%B5es+Gerenciais+-+4\%C2\%BA+trimestre+de+2018/36e91555-141a-637d97b1-9f6946cc61b3?version=1.2> Acesso em 15 de julho de 2019.

ANTONIOLLI, A. F.; DE FREITAS MOSCARDINI, E.; GESSNER, E.; PALADINI, E. P. Análise de serviço de energia solar fotovoltaica compartilhada no brasil. Revista Empreender e Inovar, v. 1, n. 1, p. 104-116, 2018.

BRASIL. Decreto no 5468. Altera as alíquotas do Imposto sobre Produtos Industrializados - IPI incidentes sobre os produtos relacionados no Decreto no 4.955, de 15 de janeiro de 2004. Publicado no dou de 16 de junho de 2005.

BRASIL. Decreto no 8950, de 29 de dezembro de 2016. Aprova a Tabela de incidência do Imposto sobre produtos industrializados -TIPI. Publicado no Dou de 30 de dezembro de 2016.

BRASIL. Lei no 13.097, de 19 de Janeiro de 2015. Reduz a zero as alíquotas da Contribuição para o PIS/PASEP, da COFINS, da Contribuição para o PIS/PasepImportação e da Cofins-Importação incidentes sobre a receita de vendas e na importação de partes utilizadas em aerogeradores; prorroga os benefícios previstos nas Leis $\mathrm{n} \cong 9.250$, de 26 de dezembro de 1995, 9.440, de 14 de março de 1997, 10.931 , de 2 de agosto de 2004, 11.196, de 21 de novembro de 2005, 12.024, de 27 de agosto de 2009 e da outras providencias. Publicado no D.O.U. de 20.1.2015.

CRESESB. Manual de Engenharia Para Sistemas Fotovoltaicos. Rio de Janeiro: Centro de Pesquisas de Energia Elétrica (CEPEL), 2014. 530 p. Disponível em:> http://www.cresesb.cepel.br/publicacoes/download/Manual de Engenharia FV 201 4.pdf >. Acesso em: 22 de julho de 2019.

ÇOBAN, O.; YORGANCILA, F. N.; ÇOBAN, A. Relationship between renewable energy consumption and sustainable economic growth: the case of Turkey. In: 2018 International Conference and Utility Exhibition on Green Energy for Sustainable Development (ICUE), 2018. p. 1-6.

CONFAZ. Convênio ICMS 101/97. Publicado no Dou de 18 de Dezembro de 1997.

DANTAS, S.G.; POMPERMAYER, F.M. Viabilidade Econômica de Sistemas Fotovoltaicos no Brasil e Possíveis Efeitos no Setor Elétrico. Texto para discussão, Rio de Janeiro, 2018. Disponível em<: http://repositorio.ipea.gov.br/handle/11058/8400> Acesso em: 25 de jullho de 2019.

EPE. Anuário Estatístico de Energia Elétrica 2018. Rio de Janeiro: [s. n.], 2018. Disponível em: > http://epe.gov.br/pt/publicacoes-dados-abertos/publicacoes/anuarioestatistico-de-energia-eletrica> Acesso em: 13 de fevereiro de 2019.

FREITAS, S.; REINHART, C.; BRITO, M. C. Minimizing storage needs for large scale photovoltaics in the urban environment. Solar Energy, v. 159, p. 375-389, 2018.

GLENN, J. C.; GORDON, T. J.; FLORESCU, E.; 2011. Futures studies around the World. In: 2011 State of the future. Washington, EUA: The millennium project, global futures studies \& research. Cap. 7 . 
IBGE. Contas regionais do Brasil 2017. Ministério do Planejamento, Orçamento e Gestão, Instituto Brasileiro de Geografia e Estatística, Diretoria de Pesquisas, Departamento de Contas Nacionais, 2019.Disponível em:> https://www.ibge.gov.br/estatisticas/economicas/contas-nacionais/9054-contasregionais-do-brasil.html?=\&t=0-que-e

MAJI, I. K. Impact of clean energy and inclusive development on CO2 emissions in sub-Saharan Africa. Journal of Cleaner Production, v. 240, p. 118186, 2019.

MARTIN, C. J. The sharing economy: A pathway to sustainability or a nightmarish form of neoliberal capitalism? Ecological Economics, v.121, 149-159. 2016.

MME. Brasil lança Programa de Geração Distribuída com destaque para energia solar. Outras notícias, [S. I.], 15 dez. 2015. Disponível em: http://www.mme.gov.br/web/guest/pagina-inicial/outras-noticas/lasset publisher/32hLrOzMKwWb/content/programa-de-geracao-distribuida-prevemovimentar-r-100-bi-em-investimentos-ate-2030. Acesso em: 5 ago. 2019.

MORETTIN, P. A.; BUSSAB, W. O. Estatística básica. Editora Saraiva, 542p, 7.ed. 2017.

NEOSOLAR. Sistemas de energia solar fotovoltaica e seus componentes. [S. I.], 2019. Disponível em:> https://www.neosolar.com.br/aprenda/saiba-mais/sistemas-deenergia-solar-fotovoltaica-e-seus-componentes. Acesso em: 25 jul. 2019.

OLSZEWSKI, R.; PAŁKA, P.; WENDLAND, A.; KAMIŃSKI, J. A Multi-Agent Social Gamification Model to Guide Sustainable Urban Photovoltaic Panels Installation Policies. Energies, v. 12, n. 15, 3019, 1-27, 2019.

PAULISTA, C. R.; MACHADO, T. S.; DE ASSIS RANGEL, J. J. Análise da expansão da geração elétrica fotovoltaica e emissões de dióxido de carbono. Revista Produção e Desenvolvimento, v. 3, n. 1, p. 12-25, 2017.

ROSA, B. Brasil perderá posição no ranking de energia limpa. O Globo, [S. I.], 21 out. 2018. Disponível em:> https://oglobo.globo.com/economia/brasil-perdera-posicao-noranking-de-energia-limpa-23173428>. Acesso em: 25 jul. 2019.

SHAKOURI, M.; LEE, H. W.; KIM, Y. W. A probabilistic portfolio-based model for financial valuation of community solar. Applied Energy, v.191, 709-726. 2017

TIEPOLO, G. M.; PEREIRA, E. B.; URBANETZ JR, J.; PEREIRA, S. V.; GONCALVES, A. R.; LIMA, F. J. L.; COSTA, R. S., ALVES, A. R. Atlas de Energia Solar do Estado do Paraná. 1a Edição. Curitiba: UTFPR, 2017.

VIDAL, A. L. Energia solar no Brasil: geração distribuída nos setores comercial e industrial. 2017. Monografia. 57P. Universidade Federal do Rio De Janeiro: Instituto de Economia. 2017. 